much resemblance to the vitreous ashes of Krakatoa, drawn on p. 587 , as they are very thin.

I have examined this sediment with the naked eye to see whether I could perceive anything like the large corona. I darkened the room and admitted the sunlight through a narrow slit on to the glass. The sediment sparkles with various colours, chietly pink and green, I suppose owing to interference ; and it is difficult to judge which colour preponderates. I find a decided excess of green at a small angular distance from the sun, and often pink preponderates at a greater but varying distance. These colours being similar to those seen in the large corona are slightly confirmatory of the theory that the sediment from the rain is the substance which has caused it and the strange sunsets and sunrises ; but other substances are also capable of giving a green light near the sun. Moisture on glass gives quite different colours, so far as I have observed.

The cirrus-like wisps on which the sunset phenomena appeared were definite and very small at the end of November; but on the whole grew larger and more indefinite, till at length they have been quite imperceptible for several weeks past.

On April 24 there was the first moderately bright aurora I have seen since October 5. Can this remarkable absence of auroras and the scarcely less remarkable frequency of lightning have been caused by the volcanic dust? If so, it may also account for S. Tromholt's finding auroras so scarce and poor in Iceland during the winter, as mentioned on p. 537 (vol. xxix.), though he does not say whether they were scarcer than usual there. Thos. Wm. Backhouse

Sunderland, May Io

\section{Pons' Comet}

Pons' comet was visible here with the naked eye throughout the month of February, including the nights of greatest moonlight. I so saw it on some twenty or more nights during that month, and append some notes as to its comparative brightness, so far as I could judge.

February 3.- "Comet visible till I0.45. Could see "old moon' with naked eye easily, and in telescope Grimaldi and Aristarchus, but only with a very small part of sunlighted portion in field."

February 6.- "At 8.45 conld see comet with naked eye, though sky not quite free of sunset-glow and somewhat hazy, and moon nine days old. It was altogether faint, but most of the tail visible at other times could be seen-certainly more than I should have expected."

February 9.- "At 9.30 found the comet with naked cye and could see it without difficulty, but there was only the suggestion of a tail. Comparing it with $\alpha$ Sculptoris by looking miclway between the two, they produced the same effect on the eye; but of course the least magnifying power showed the difference."

February 10.- " 8.20 to 8.50 . Found comet with naked eye, but it was very faint, and to the unaided eye looked certainly fainter than a Sculptoris. Yet it secmed to me that more of the tail (or the tail more certainly) was visible than last night."

February II.- " Found comet with naked eye about 8. Io, and watched it up to 9.40. As the sky lost the traces of sunset I could pick it up without difficulty, in spite of the full moon shining in a cloudless sky. It was not quite so easily seen as $\alpha$ Sculptoris, but I may say that $\lambda^{1}$ and $\lambda^{2}$ Sculptoris, though each marked as of the same magnitude as $\alpha$, I could not get a glimpse of, though I tried hard."

February 12.- "At 8. I 5 found comet with naked eye without difficulty, and so at intervals up to 9. Found it again with difficulty at 10.15 ; it was then getting low and into the haze : in the telescope it seemed then to have lost (at a guess) half it light."

On the subsequent clear nights in February there was no clifficulty.

March has been much cloudier, and owing to this and moonlight I only saw it with naked eye certainly on four nights--the Ist, 4th, I6th, and 17th. My note for the 4 th is : "Found and saw comet with naked eye several times, though not easily, between 8.15 and $8.40 \mathrm{p.m}$. Could see the outline of the "old moon' without difficulty."

The 5 th is marked as doubtful both as to comet and "old moon."

March 14. - "A fine pink glow in evening, and splendid afterglow about 7.15-never saw it better. Found comet easily with opera-glass, but could not see it with naked eye, the moon rising before the glow had vanished." So also on the 15 th.
March I6._-"Saw comet repeatedly with naked eye (looking a little above it) between 7.45 and 8.30 . Sky very good."

March I 7, 7.40 to 8. 10.- " Found comet with naked eye, and saw it many times, looking a little above it; could not be quite sure of seeing it direct."

Owing to clouds I have only seen it on two nights since, the $24^{\text {th }}$ and 28 th ; and that only with opera-glass and telescope.

Nelson, N.Z., March 29

A. S. ATKINSON

\section{Snow and Ice Flora}

In the account of Prof. Veit Brecher Wittrock's interesting work on the Arctic snow and ice flora (NATURE, vol. xxviii. p. 304) your reviewer enumerates the countries and mountain ranges where red snow has been observed, but does not mention the Southern Alps of New Zealand, where as far back as I86 I this plant was observed by me. The fact that green and red ice have been found in these high northern latitudes, and that the unusual coloration has been traced to microscopic organic life is of special interest to me, as I repeatedly observed green as well as red ice amongst the glaciers of New Zealand, first at the head of the Rangitata. River, as far back as February, 186r. At the time I published an account of this occurrence, which was reprinted by others (amongst others see Hochstetter's "Neu Seeland," $1863, \mathrm{p} \cdot 342$ ). Since then during my alpine explorations I have repeatedly observed the same phenomenon, so that evidently at the Antipodes there occurs a counterpart of the Arctic snow and ice flora. It is to be hoped that some able botanist will some day do the same work for us that Baron Nordenskjold and his able coadjutors have done for Greenland and Spitzbergen.

Christchurch, N.Z., December 31, 1883

\section{The Rotation Period of Mars}

NotwithstANDING his comparatively small diameter and slow axial motion, the planet Mars affords special facilities for the exact determination of the rotation period. Indeed no other planet appears to be so favourably circumstanced in this respect, for the chief markings on Mars have been perceptible with the same definiteness of outline and characteristics of form through many succeeding generations, whereas the features such as we discern on the other planets are either temporary atmospheric phenomena or rendered so indistinct by unfavourable conditions as to defy lengthened observation. Moreover it may be taken for granted that the features of Mars are permanent objects on the actual surface of the planet, whereas the markings displayed by our telescopes on some of the other planetary members of our system are mere effects of atmospheric changes which, though visible for several years and showing well-defined periods of rotation, cannot be accepted as affording the true periods. The behaviour of the red spot on Jupiter may closely intimate the actual motion of the sphere of that planet, but markings 'of such variable unstable character can hardly exhibit an exact conformity of motion with the surface upon which they are seen to be projected. With respect to Mars the case is entirely different. No substantial changes in the most conspicuous features have been detected since they were first confronted with telescopic power, and we do not anticipate that in future ages there will be any material difference in their general configurations. The same markings which were indistinctly revealed to the eyes of Fontana and Huyghens in 1636 and 1659 , will continue to be displayed to the astronomers of succeeding generations, though with greater fulness and perspicuity owing to improved means. True there may possibly be variations in progress as regards some of the minor features, for it has been suggested that the visibility of certain spots have varied in a manner which cannot be satisfactorily accounted for on ordinary grounds. These may possibly be due to atmospheric effects on the planet itself, but in many cases the alleged variations have doubtless been more imaginary than real. The changes in our own climate are so rapid and striking, and occasion such abnormal appearances in celestial objects that we are frequently led to infer actual changes where none have taken place ; in fact, observers cannot be too careftil to consider the origin of such clifferences and to look nearer home for some of the discordances which may have become apparent in their results.

The rotation period of Mars has been already given with so much precision that it may seem superfluous to rediscuss the point, but it is very advisable to see whether recent observations 